\title{
Композитные графен-содержащие пористые материалы для электросорбции и емкостной деионизации воды
}

\author{
(C) 2020 Бахия Тамуна ${ }^{1}$, Хамизов P.X. ${ }^{2}$, Бавижев 3.P. ${ }^{3}$ \\ ${ }^{1}$ Московский государственный университет имени М.В. Ломоносова, Москва \\ ${ }^{2}$ Институт геохимии и аналитической химии имени В.И. Вернадского Российской академии наук \\ (ГЕОХИ РАН), Москва \\ ${ }^{3}$ Научно-исследовательский центтр акиионерного общества «Радий», Москва
}

Поступила в редакцию 1.06.2020 г.

DOI: $10.17308 /$ sorpchrom.2020.20/2869

Высокопористые аэрогели на основе углеродных наноматериалов - перспективные материалы для новых электрохимических технологий. Емкостная деионизация воды - удаление ионов из водного раствора путем приложения малых значений внешнего напряжения к электродам с большой удельной поверхностью. Данный метод является на сегодняшний день одним из наиболее перспективных для опреснения растворов с низкой минерализацией.

Основная проблема для емкостной деионизации заключается в получении доступных электродных материалов с высокой пористостью, электропроводностью, гидрофильностью и хорошими механическими свойствами для использования в течение большого количества циклов адсорбциидесорбции. Для этих целей углеродные аэрогели являются одними из наиболее перспективных материалов.

Статья посвящена синтезу новых материалов - высокопористых монолитных композитных аэрогелей с пространственной трехмерной структурой, образованной восстановленным оксидом графена и нанотрубками; исследованию их электросорбционных свойств в экспериментах с использованием указанных монолитов в качестве электродов для емкостной мембранной деионизации воды.

Предложены новые методы синтеза углеродных высокопористых композитных аэрогелей, где каркас представлен восстановленным оксидом графена и углеродными нанотрубками. Разработаны простые методики по гидрофилизации синтезированных образцов. Изготовлены новые электродные материалы для электросорбции, исследованы и испытаны в электрохимических ячейках для мембранной емкостной деионизации. Сверхпористые (более 99\%) углеродные композитные аэрогели с

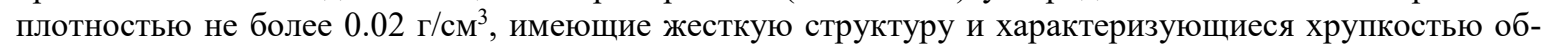
разующихся монолитов, не эффективны в процессах емкостной мембранной деионизации. Эластичные аэрогели с более плотной структурой, пористостью до 95\% и плотностью не менее 0.12 г/см, синтезированные в присутствии поливинилового спирта, имеют относительно высокую электросорбционную емкость по отношению к хлориду натрия. К примеру, если концентрация раствора 1 г/дм³,

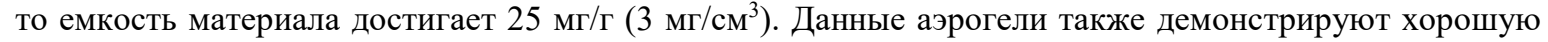
стабильность, что делает их очень перспективными для использования в технологиях емкостной деионизации.

Ключевые слова: графен, аэрогель, мезопористый углерод, композит, емкостная деионизация.

\section{Введение}

Интерес к синтезу и получению углеродных наноструктур связан прежде всего с перспективами создания уникальных материалов и изделий на их основе для практического использования в энергетике, охране окружающей среды, для изготовления высокопористых и селективных сорбентов, суперконденсаторов и систем 
опреснения нового поколения. Высокопористые углеродные аэрогели являются очень перспективными материалами для новых электрохимических технологий. Емкостная деионизация воды (ЕД), а именно, удаление ионов из водного раствора путем приложения малых значений внешнего напряжения к электродам с большой удельной поверхностью при отсутствии токов электролиза является на сегодняшний день одним из наиболее перспективных методов опреснения растворов с низкой минерализацией. Обратимость процесса ЕД делает в перспективе возможной рекуперацию электроэнергии, и в будущем данный метод будет конкурировать с наиболее экономичными технологиями, используемыми сегодня, включая технологию обратного осмоса [1]. Историческая справка, экспериментальные подходы к эксплуатации и тестированию ЕД приведены в обзорах $[1,2]$. Однако, в классическом способе ЕД трудно контролировать процесс десорбции ионов, например, путем изменения полярности напряжения на пористых электродах, поскольку высвобождение ионов и образование концентрата сопровождаются последующей деионизацией в противоположном направлении.

В 2004 году авторы из компании Биосорс [3] запатентовали методику, которая впоследствии стала известна как емкостная мембранная деионизация (ЕМД) и которая позволила регулировать стадию десорбции и повысить эффективность и разделительную способность процесса опреснения в циклическом режиме электросорбции - электродесорбции. Отличительной особенностью этого подхода является то, что в электрохимическую ячейку помещают катионообменную и анионообменную мембраны так, чтобы они примыкают к электродам изнутри, как показано на рис. 1. Такая ячейка работает в режиме деионизации только при одной полярности, когда катодный потенциал подается на верхний электрод. При смене полярности возможно только высвобождение ионов в свободный объем и образование концентрата.

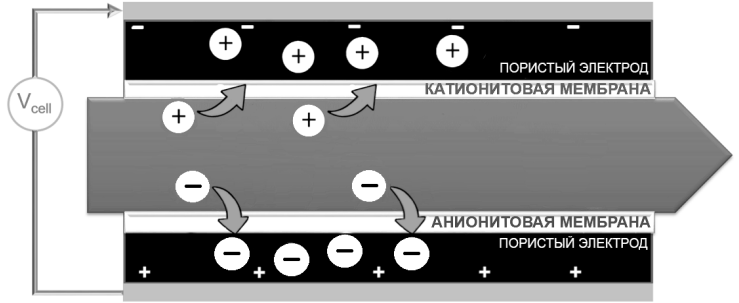

a

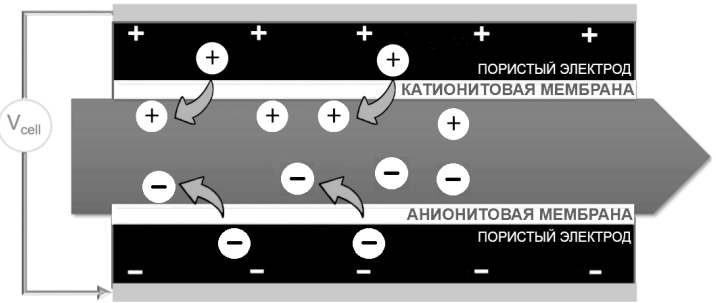

6

Рис. 1. Схема емкостной мембранной деионизации:

(а) электросорбция и деионизация; (б) десорбция

Основная проблема для емкостной деионизации заключается в получении доступных электродных материалов с высокой пористостью, электропроводностью, гидрофильностью и хорошими механическими свойствами для использования в течение большого количества циклов адсорбции-десорбции. Углеродные аэрогели являются одними из наиболее перспективных материалов для этих целей [4]. Однако существующие методы применяются для получения гидрофобных сорбционных материалов, которые применяются для сбора нефти и нефтепродуктов [5].

Кроме того, некоторые методы синтеза аэрогелей требуют использования токсичных химических веществ, таких как гидразин, для химического восстановления оксида графена (ОГ). Авторами статьи был предложен более экологичный способ получения композитного аэрогеля [6]. Этот метод позволяет использовать графит и многослойные углеродные нанотрубки (МУНТ) в качестве исходного сырья и основан на модифицированном методе Хаммерса для получения ОГ, а также на некоторой последовательности основных операций, описанных в работе [5], кроме 
трех принципиальных отличий: химическое восстановление ОГ осуществляется с использованием глюкозы; на разных этапах предложенной методики используется микроволновое излучение для разрушения непрореагировших органических остатков, а также для повышения эффективности восстановления; разработана и используется специальная дополнительная стадия гидрофилизации конечного продукта [6].

Данная статья посвящена синтезу новых материалов - высокопористых монолитных композитных аэрогелей с пространственной трехмерной структурой, образованной восстановленным оксидом графена и нанотрубками, а также исследованию их электросорбционных свойств в экспериментах с использованием указанных монолитов в качестве электродов для емкостной мембранной деионизации воды.

\section{Экспериментальная часть}

Получение композитных аэрогелей. Синтезировали два типа аэрогелей с разной пористостью, которые обозначали как «легкий» и «плотный» образцы.

В экспериментах по синтезу использовали следующие исходные материалы: сухой коллоидный графитовый препарат из природного графита марки C-1 (Россия); многостенные углеродные нанотрубки (МУНТ от компании Deatlom, с внутренним диаметром 2-20 нм, внешним диаметром 35-100 нм, длиной (макс.) - 5 мкм, электропроводностью $\left.-0.5 \mathrm{MCM}^{-1}\right)$; железная пластина (10x10x1 мм).

Использовали следующие реагенты квалификации «чда»: $\mathrm{KMnO}_{4}, \mathrm{H}_{2} \mathrm{SO}_{4}$ (конц.), $\mathrm{HNO}_{3}$ (конц.), $\mathrm{H}_{2} \mathrm{O}_{2}\left(30 \%\right.$,) $\mathrm{P}_{2} \mathrm{O}_{5}, \mathrm{~K}_{2} \mathrm{~S}_{2} \mathrm{O}_{8}, \mathrm{HCl}$ (конц.), а также реагенты квалификации «хч»: глюкоза и поливиниловый спирт. Кроме того, использовали этиловый спирт (96\%), поливинилпирролидон (со степенью полимеризации около 10000), а также деионизированная вода с удельным сопротивлением не менее 1 МОм·см.

Синтез легкого аэрогеля. Первая стадия (синтез оксида графена). Графитовые хлопья весом 5 г смешивали в течение дня со смесью концентрированной серной и азотной кислот, взятых в объемном соотношении 3:1. Смесь разбавляли деионизированной водой и фильтровали. Осадок промывали деионизированной водой, высушивали при $60^{\circ} \mathrm{C}$ и обрабатывали микроволновым излучением $\left(950 \mathrm{BT} / 20\right.$ дм $\left.^{3}\right)$ в течение 3 минут. 1.5 г полученного продукта, $300 \mathrm{~cm}^{3}$ серной кислоты, 4.2 г персульфата калия, 6.2 г фосфорного ангидрида помещали в колбу и перемешивали в течение 5 часов при температуре $80^{\circ} \mathrm{C}$. Смесь охлаждали до комнатной температуры, фильтровали и промывали деионизированной водой. Осадок сушили. Весь синтезированный порошок и 15 г перманганата калия медленно (в течение часа) помещали в концентрированную серную кислоту при температуре $0^{\circ} \mathrm{C}$. Полученную суспензию перемешивали в течение двух часов при $35^{\circ} \mathrm{C}$, после чего ее разбавляли деионизированной водой, а затем добавляли $10 \mathrm{~cm}^{3}$ пероксида водорода. Полученный коллоидный раствор оставляли на ночь. После этого его центрифугировали (5000 об/мин) в течение 20 минут, промывали водой и $1 \mathrm{M}$ соляной кислотой. Полученный оксид графена диспергировали в воде с помощью ультразвуковой обработки.

Вторая стадия. Смешивали 75 мг МУНТ, 0.75 мг поливинилпирролидона, $30 \mathrm{~cm}^{3}$ этанола; смесь обрабатывали в ультразвуковой ванне в течение 5 часов для получения коллоидной дисперсии углеродных нанотрубок. Затем эту же дисперсию и ранее диспергированный оксид графена объединяли в массовом соотношении 15:1, добавляли 0.1 г глюкозы. Смесь нагревали и перемешивали при $95^{\circ} \mathrm{C}$ в течение часа, а затем оставляли при комнатной температуре еще 2 часа.

Третья стадия. Полученную смесь лиофилизировали для получения монолитного аэрогеля на основе восстановленного оксида графена и углеродных нанотрубок. Синтезированный материал обрабатывали в микроволновой печи в течение пяти минут (950 Вт/20дм³).

Бахия и др. / Сорбционные и хроматографические процессы. 2020. Т. 20. № 3. С. 320-334 
Четвертая стадия. Для гидрофилизации полученного материала его обрабатывали в смеси разбавленной азотной кислоты (5\%) и перекиси водорода $(1 \%)$ в течение 10 минут при комнатной температуре.

Синтез плотного аэрогеля. Повторяли вышеизложенную методику за исключением следующих операций на второй стадии: а) в коллоидный раствор помещали катализатор: железную пластинку размером 10х10х1мм в соответствии с методикой, предложенной в [7]; б) после восстановления глюкозой (в присутствии $\mathrm{Fe}$ ) к коллоидной смеси восстановленного оксида графена и углеродных нанотрубок добавляли $5 \%$ (по массе) поливинилового спирта и перемешивали в течение 2 часов при температуре $60^{\circ} \mathrm{C}$. Электроды нужного размера для ЕМД вырезали вручную из синтезированных монолитных материалов.

Методы исследования, использованные в работе. Спектры комбинационного рассеяния получали на спектрометре/микроскопе Renishaw InVia Reflex с использованием лазера с длиной волны 514 нм (зеленый). Снимки растровой электронной микроскопии получали с помощью микроскопа Carl Zeiss NVision 40 (3000x300000x). Спектры рентгеновской фотоэлектронной спектроскопии получали на спектрометре Kratos Axis Ultra DLD РФЭС.

Определение площади поверхности и порометрию образцов проводили методом капиллярной сорбции азота на анализаторе сорбции газов Quantachrome NOVA 4200e. При этом использовали модель Брунауэра-Эммета-Теллера (БЭТ) - для определения удельной площади поверхности, и метод Барретта-Джойнера-Халенды (БДХ) - для анализа распределения пор по размерам.

Электропроводность синтезированных образцов аэрогелей измеряли в ячейке ProboStat (Norecs) обычным двухэлектродным методом и методом Ван-дер-Пау (4контактным). При этом измерения проводимости постоянного тока выполняли с использованием потенциостата Autolab PGSTAT302N/гальваностата в режиме циклической вольтамперометрии (BAX). Электропроводность растворов измеряли с помощью кондуктометра «Эксперт-002-2-6-П» (датчик лабораторный).

Материалы и реагенты для лабораторной установки по емкостной (мембранной) деионизации. Использовали монополярные гетерогенные ионообменные мембраны марок МК-40 и МА-41 (ООО «Инновационное предприятие «Щекиноазот», Россия), токопроводящую ленту (SPI Supplies, 12 мм х 20 м), а также $\mathrm{NaCl}$ (х.ч.).

\section{Обсуждение результатов}

Синтез композитного аэрогеля. Последовательность основных этапов методики синтеза [6] представлена на рис.2. Существуют различные модификации метода Хаммерса, основанные на введение дополнительных атомов и молекул между молекулярными слоями в графите в кислой среде с последующим разделением этих слоев. Методика, использованная нами на первом этапе синтеза, наиболее близка к «улучшенному» методу Хаммерса, предложенному в работе [8].

Полученный оксид графена (в смеси с многослойными углеродными нанотрубками) подвергается химическому восстановлению и сублимационной сушке для получения трехмерной пористой структуры. На стадии восстановления глюкоза использовалась без дополнительных добавок. Это более слабый реагент, чем глюкоза с аммиаком, гидразином и некоторыми другими восстанавливающими веществами, но создает возможность экологически безопасного процесса. Впервые подобная методика получения графена из ОГ была использована в работе [9]. Известно, что помимо реакции восстановления (I) с образованием альдоновой кислоты [10] происходит дополнительный процесс функционализации, а именно, химическое присоединение 
остатков глюкозы к восстановленному оксиду графена [11], например, в соответствии со следующей реакцией (II):

$$
\text { (I) }
$$

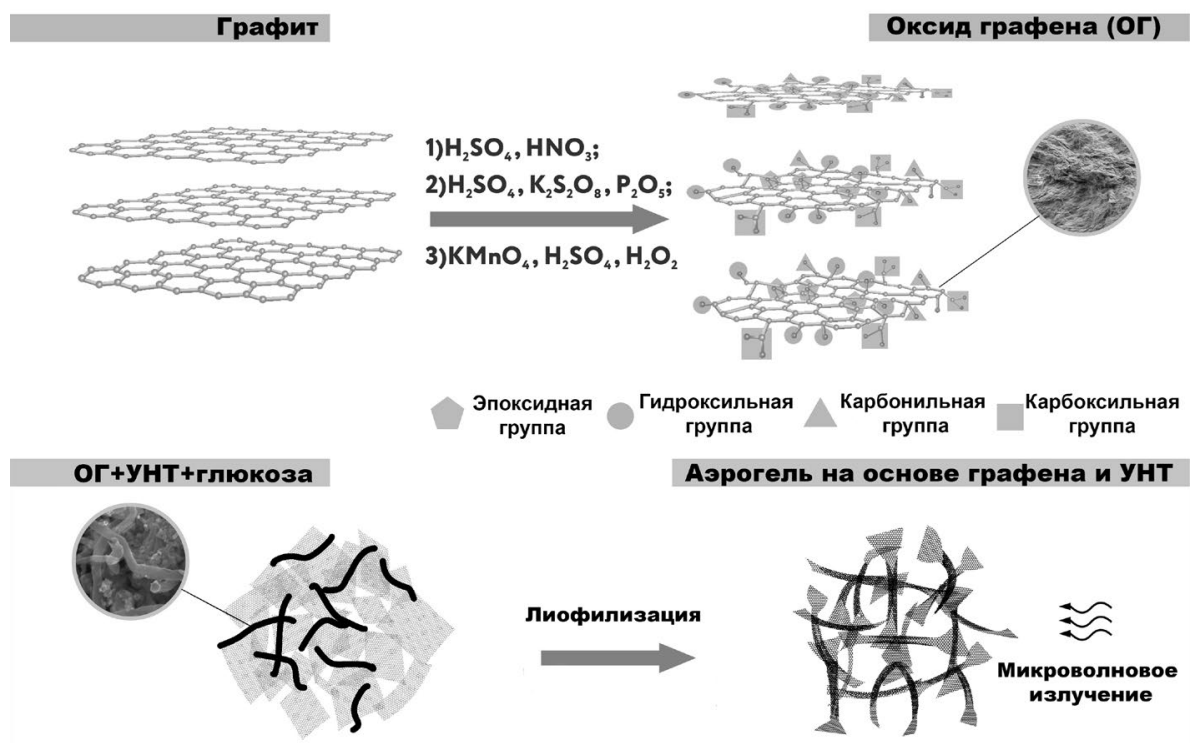

Рис. 2. Основные стадии получения аэрогеля

Для разрушения этих органических остатков перед стадией гидрофилизации используется интенсивная микроволновая обработка полученного аэрогеля в виде твердого монолита. Образцы обоих типов композитного аэрогеля, «легкий» и «плотный», были получены в соответствии с приведенной схемой. Легкий образец был более хрупким. Плотный аэрогель получали с использованием дополнительной стадии синтеза, описанной в [7]: для более эффективного восстановления оксида графена вместе с глюкозой применяли железо в качестве катализатора. Кроме того, плотный образец, как будет видно позже, обладал упругостью, для достижения которой после обработки глюкозой в горячую реакционную смесь добавляли поливиниловый спирт. Такой подход ранее был описан в работе [8].

Гидрофилизация композитного материала. Метод, использованный для синтеза аэрогеля на основе восстановленного оксида графена и углеродных нанотрубок, приводит к получению материала с гидрофобными свойствами [5]. Соответственно, оба образца, полученные по методике, описанной выше, изначально не смачивались водой. Материалы были получены в виде монолитов. Более плотный образец имел упругие свойства и не разрушался при многократном изгибе (рис. 3). Образцы полученных материалов с известной массой использовали для определения их общей плотности, для чего их погружали в воду, затем их гидрофилизировали в соответствии с процедурой, описанной в патенте [6]: обработкой разбавленным раствором 
смеси азотной кислоты и перекиси водорода. На рис. 3 приведены снимки синтезированных образцов до и после гидрофилизации.
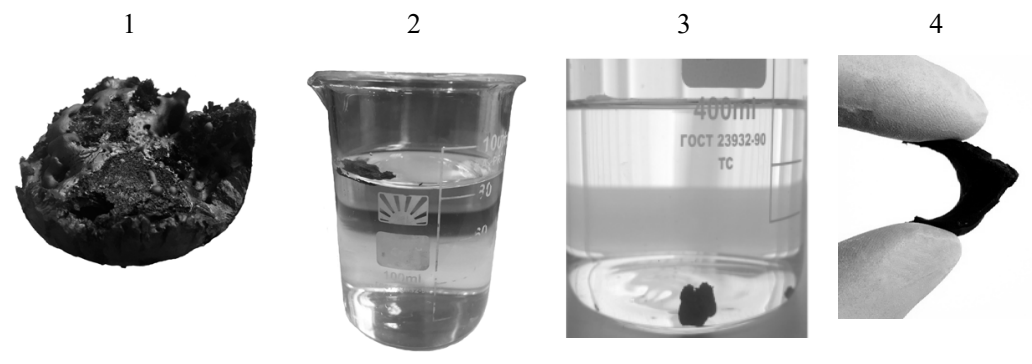

Рис. 3. Фотографии полученных образцов аэрогеля: 1 - «легкий» образец; 2,3 - до и после его гидрофилизации; 4 - «плотный» образец.

Эта процедура чрезвычайно важна, так как гидрофилизация включает в себя химическую модификацию с присоединением определенного количества функциональных групп. Необходимо проводить ее так, чтобы появилась смачиваемость, но не ухудшалась электропроводность. Обработка разбавленным раствором перекиси водорода и азотной кислоты приводит к таким результатам, как видно из данных, приведенных в таблице 1.

Таблица 1. Некоторые основные свойства образцов композитного аэрогеля.

\begin{tabular}{|c|c|c|c|c|}
\hline Образец & $\begin{array}{c}\text { Электропроводность } \\
\text { до гидрофилизации, } \\
\text { мСм/м }\end{array}$ & $\begin{array}{c}\text { Электропроводность } \\
\text { после гидрофилиза- } \\
\text { ции, мСм/м }\end{array}$ & $\begin{array}{c}\text { Плотность } \\
\text { монолитного } \\
\text { материала }(\rho), \\
\text { г/см }\end{array}$ & $\begin{array}{c}\text { Пористость, } \\
\varepsilon \cdot 100 \%\end{array}$ \\
\hline 1 (легкий) & 2000 & 2000 & 0.02 & 99.1 \\
\hline 2 (плотный) & 1900 & 1900 & 0.12 & 95.0 \\
\hline
\end{tabular}

Плотность исходного гидрофобного монолитного материала $\left(\rho=m / V_{\text {воды }}\right)$ рассчитывалась как отношение массы образца к объему вытесненной воды при помещении образца в воду. Для оценки пористости было учтено, что многослойный графен, образующий каркас композитного аэрогеля, должен иметь ту же плотность, что и графит: $\rho_{0}=2.2$ г $/ \mathrm{cm}^{3}$. В этом случае пористость $\varepsilon$ можно выразить следующим образом: $\rho=\varepsilon \rho_{\text {возд. }}+(1-\varepsilon) \rho_{0} \approx(1-\varepsilon) \rho_{0}$, где $\rho_{\text {возд. }}=1.28 \cdot 10^{-3} \Gamma / \mathrm{cm}^{3}-$ плотность воздуха:

$$
\varepsilon \approx 1-\rho / \rho_{0}
$$

Изучение свойств синтезированных композитных аэрогелей. Представленные ниже результаты позволяют понять, почему электропроводность практически не меняется при гидрофилизации образцов аэрогеля. В таблице 2 представлены некоторые результаты рентгеновской фотоэлектронной спектроскопии, которые показывают наличие кислорода в составе различных функциональных групп и их фрагментов на поверхности аэрогеля до и после гидрофилизации. Видно, что предлагаемый способ гидрофилизации приводит к незначительной дополнительной функционализации поверхности, что позволяет сохранить электропроводность, но в то же время получить гидрофильный образец.

Большой интерес представляет морфология поверхности синтезированных образцов композитных аэрогелей. Эта характеристика позволяет судить о том, как устроена трехмерная структура полученных монолитов и могут ли из них быть получены стабильные пористые электроды для электросорбции и емкостной деионизации. На рис. 4 показаны электронные микрофотографии рпазличных участков по- 
верхности образца легкого композитного аэрогеля при одном и том же увеличении. Одними из основных элементов структуры являются по-разному сложенные графеновые листы, соединенные друг с другом. Кроме того, показанные снимки практически идентичны микрофотографиям, представленным в статье [9].

Таблица 2. Содержание кислорода (в атомных процентах) в составе функциональных групп и их фрагментов на поверхности различных образцов.

\begin{tabular}{|c|c|c|c|c|}
\hline \multirow{2}{*}{ Образец } & \multicolumn{2}{|c|}{ Функциональные группы и их фрагменты } & Общее содер- \\
\cline { 2 - 3 } & $\mathrm{O}-\mathrm{C}=\underline{\mathrm{O}}, \mathrm{O}=\mathrm{C}$ & $\begin{array}{c}\mathrm{C}-\mathrm{O}-\mathrm{C}, \\
\mathrm{OH}-\mathrm{C}\end{array}$ & $\underline{\mathrm{O}}-\mathrm{C}=\mathrm{O}$ & $\begin{array}{c}\text { жание, } \\
\text { ат. \% }\end{array}$ \\
\hline Оксид графена & 3.47 & 24.05 & 3.27 & 30.79 \\
\hline $\begin{array}{c}\text { Аэрогель } \\
\text { после гидрофилизации }\end{array}$ & 4.32 & 20.80 & 3.27 & 28.39 \\
\hline $\begin{array}{c}\text { Аэрогель } \\
\text { до гидрофилизации }\end{array}$ & 4.07 & 19.29 & 2.63 & 25.99 \\
\hline
\end{tabular}
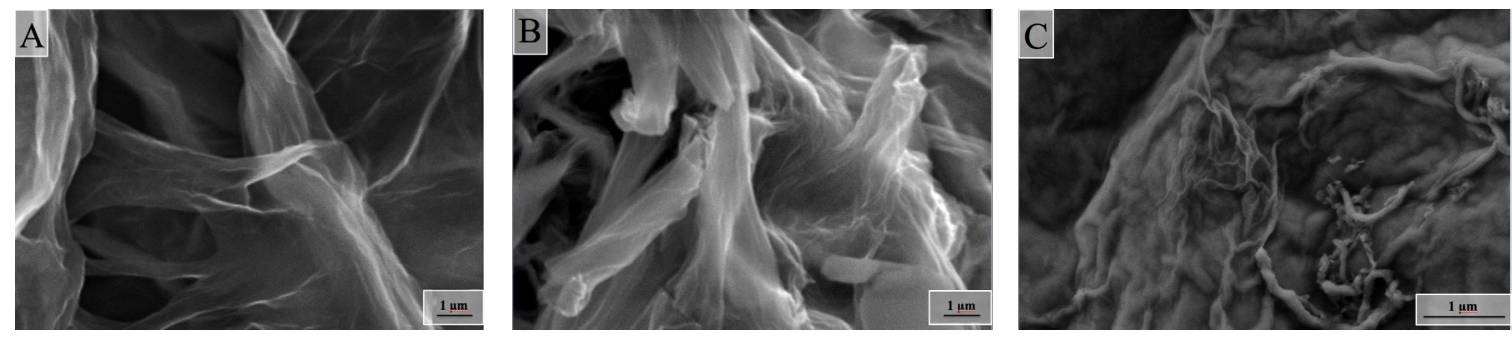

Рис. 4. Микрофотографии легкого образца композитного аэрогеля на основе графена и МУНТ.

Однако авторы статьи полагают, что им удалось синтезировать трехмерную «пиларовую» структуру, в которой нанотрубки играют роль «колонн», связывающих и удерживающих графеновые листы вместе. Мы предполагаем, что трехмерные структуры возникают при восстановлении оксида графена (в процессе уменьшения эффективного поверхностного заряда): часть листов графена самопроизвольно складывается и химически сшивается с другими листами (или стопками листов).

Это означает, что роль «колонн» играют не нанотрубки, а рулонные листы из восстановленного оксида графена. Многослойные нанотрубки могут играть роль связующего звена, но, как видно на изображении С, они в основном расположены не поперек, а вдоль поверхностей листов графена. Предположение о том, что сложенные листы могут быть химически связаны друг с другом или с другими несложенными листами, согласуется с результатами рентгеновской фотоэлектронной спектроскопии поверхности образца легкого гидрофилизированного аэрогеля. О такой возможности свидетельствуют данные, приведенные в таблице 3, из которых видно сравнимое количество атомов углерода, включенных в связь С-C с $\mathrm{sp}^{2}$ и $\mathrm{sp}^{3}$ гибридизацией для образца на основе восстановленного оксида графена.

На рис. 5 приведены снимки поверхности образца «плотного» аэрогеля, сделанных с помощью сканирующего электронного микроскопа при различных увеличениях. При внимательном рассмотрении изображения В можно увидеть в правом верхнем углу тонкие нити из нанотрубок, которые расположены радиально к внутренней поверхности макропор, подтверждая принципиальную возможность структуры, описываемой в работе [9]. 
Таблица 3. Содержание элементов, энергии связи и доли компонентов для «легкого» аэрогеля.

\begin{tabular}{|c|c|c|c|c|}
\hline Спектр & $\begin{array}{c}\text { Содержание эле- } \\
\text { мента, ат. \% }\end{array}$ & $\begin{array}{c}\text { Энергия связи, } \\
\text { эВ }\end{array}$ & Доля, ат. \% & Тип связи \\
\hline \multirow{4}{*}{$\mathrm{O} 1 \mathrm{~s}$} & \multirow{4}{*}{29.06} & 530.3 & 0.67 & $\mathrm{O}^{-}$ \\
\hline & & 531.4 & 4.32 & $\mathrm{O}-\mathrm{C}=\underline{\mathrm{O}}, \mathrm{O}=\mathrm{C}$ \\
\hline & & 532.5 & 20.80 & $\mathrm{C}-\mathrm{O}-\mathrm{C}, \mathrm{OH}-\mathrm{C}$ \\
\hline & & 533.4 & 3.27 & $\underline{\mathrm{O}}-\mathrm{C}=\mathrm{O}$ \\
\hline \multirow{5}{*}{$\mathrm{C} 1 \mathrm{~s}$} & \multirow{5}{*}{70.94} & 284.2 & 15.77 & $\mathrm{C}-\mathrm{C}\left(\mathrm{sp}^{2}\right)$ \\
\hline & & 284.9 & 19.58 & $\mathrm{C}-\mathrm{C}\left(\mathrm{sp}^{3}\right)$ \\
\hline & & 286.8 & 28.70 & $\mathrm{C}-\mathrm{O}-\mathrm{C}, \mathrm{C}-\mathrm{OH}$ \\
\hline & & 287.9 & 3.40 & $\mathrm{C}=\mathrm{O}, \mathrm{O}-\mathrm{C}-\mathrm{O}$ \\
\hline & & 288.7 & 3.49 & $\mathrm{O}=\mathrm{C}-\mathrm{O}$ \\
\hline
\end{tabular}
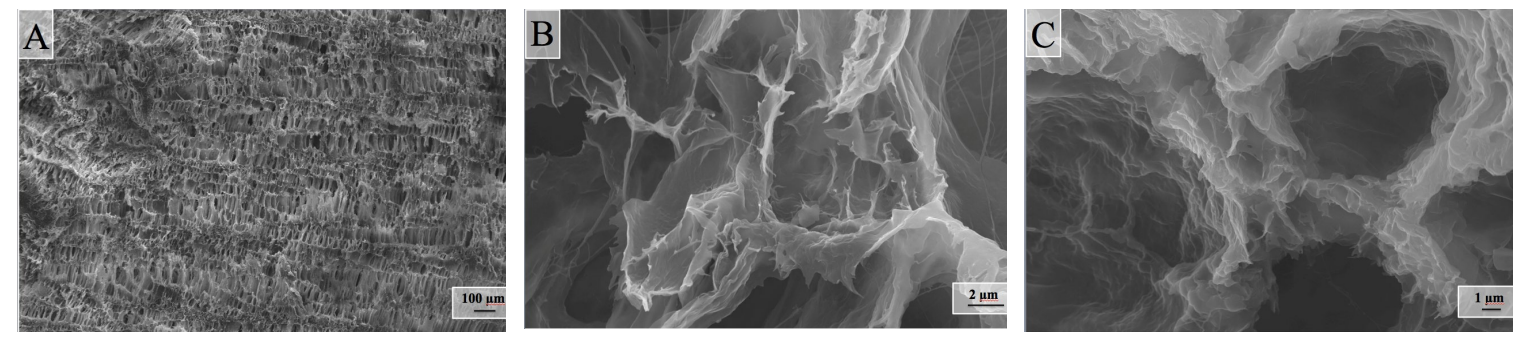

Рис. 5. Микрофотографии более плотного образца аэрогеля на основе графена и МУНТ.

Тем не менее можно полагать, что и здесь, благодаря взаимодействию листов восстановлению оксида графена, создается трехмерная монолитная структура. Это также согласуется со спектрами комбинационного рассеяния исходных материалов и синтезированных образцов аэрогеля, показанными на рисунке 6 , из которых видно, что восстановление оксида графена приводит лишь к частичному уменьшению Dпика по сравнению с G-пиком. Сильный эффект химического взаимодействия атомов углерода из разных слоев при низком содержании функциональных групп с атомами кислорода, вероятно, наблюдается и в случае с многослойными нанотрубками, спектр комбинационного рассеяния которых показан на рисунке 6 .

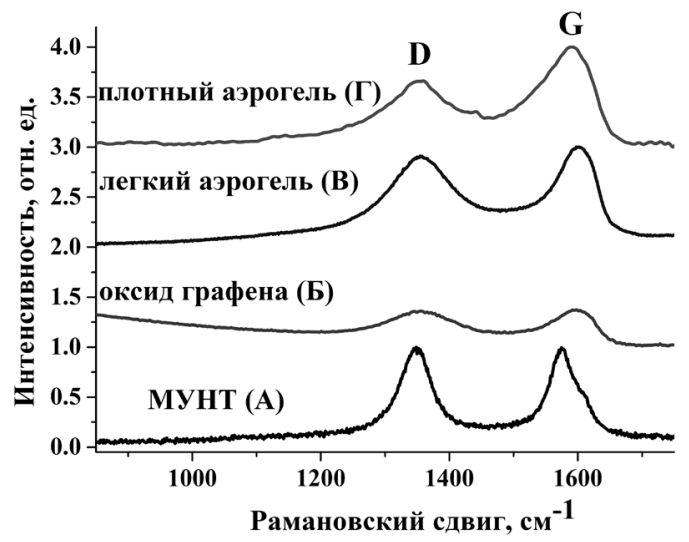

Рис. 6. Спектры комбинационного рассеяния углеродных нанотрубок (А), оксида графена (Б), легкого (В) и плотного (Г) углеродного аэрогеля.

Как было видно на рис. 4-5, основную часть пор аэрогелей формируют макропоры. Однако следует отметить, что только мезопоры важны в процессах емкост- 
ной деионизации. Гидратированные ионы не могут проникать в поры атомных размеров. В то же время и макропоры не могут обеспечить основное условие для емкостной деионизации: содержимое раствора в поре должно помещаться на его внутренней поверхности. Если $C$ - концентрация соли (пусть это будет $\mathrm{NaCl}$ ) в исходном перерабатываемом растворе, а $S$ - поверхностная концентрация соли на стенках пор, то мы можем приблизительно оценить необходимые значения размеров пор для процесса емкостной деионизации. Для одной поры с диаметром $d$ очевидно, что:

$$
\pi d^{2} S=\frac{1}{6} \pi d^{3} C
$$

У. Орен [1] оценивает сорбционную емкость поверхности углеродных мате-

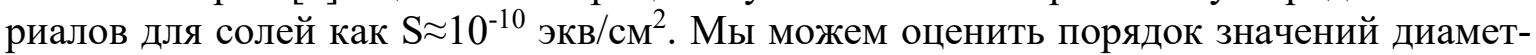
ров, для которых процесс емкостной деионизации может протекать при различной начальной концентрации раствора соли. Эти оценки приведены в таблице 4.

Таблица 4. Приблизительные диаметры мезопор, при которых возможен процесс емкостной деионизации растворов различной концентрации.

\begin{tabular}{|c|c|c|c|}
\hline $\mathrm{C}$, эКВ/дм & \\
\hline $\mathrm{C}_{\mathrm{NaCl}}, \Gamma / \mathrm{LM}^{3}$ & 0.01 & 0.1 & 1.0 \\
\hline $\mathrm{d}, \mathrm{HM}$ & 0.6 & 5.9 & 58.5 \\
\hline
\end{tabular}

Очевидно, строгая оценка требует сложного моделирования, включающего учет большого числа факторов. Такие модели, основанные на решении уравнения Пуассона для заданных граничных условий и позволяющие вычислять распределение потенциала и концентрации компонентов в порах, приведены в работах $[1,10]$.

Рассмотрим характеристики мезопор для синтезированных образцов композитных аэрогелей, исследованных методом низкотемпературной сорбции (десорбции) азота. Результаты, представленные на рисунке 7 и полученные с использованием метода БДХ, позволяют нам увидеть распределение пор по размерам в диапазоне от атомных размеров до нескольких десятков нм.

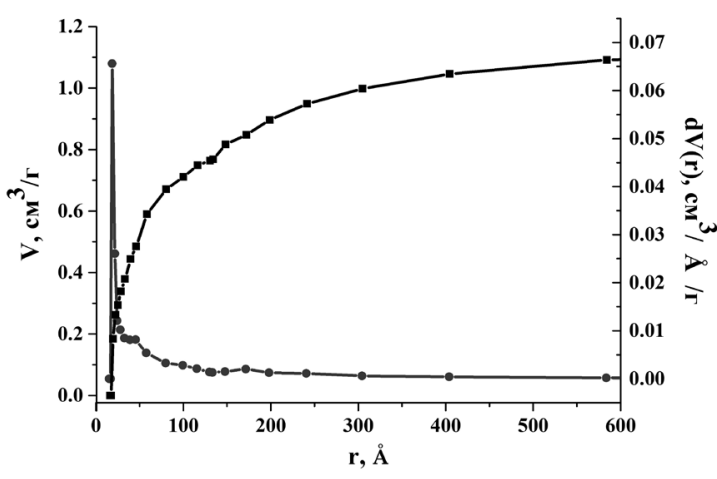

a

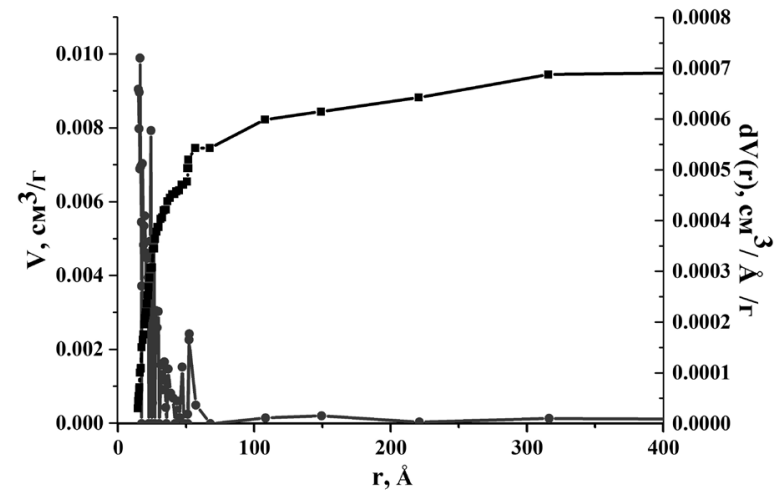

6

Рис. 7. Удельные объемы пор и распределение пор по размерам для легких (a) и плотных (б) композитных аэрогелей.

Видно, что это распределение имеет разный характер для двух образцов аэрогелей. В легком образце сформировались поры схожих типов со средним размером диаметра порядка 2 нм.

Расчеты по модели БЭТ показывают, что поверхность мезопор составляет около $290 \mathrm{~m}^{2} /$ г. В плотном образце мезопоры находятся в основном в диапазоне размеров радиусов от 1 до 7 нм, где средний радиус пор=1.66 нм, а площадь поверхности оценивается как $350 \mathrm{~m}^{2} / \Gamma$. 
Организация процесса емкостной (мембранной) деионизации. На рисунке 8 показана схема лабораторной установки по емкостной (мембранной) деионизации и конструкция электрохимической ячейки, а также приведены соответствующие фотографии.
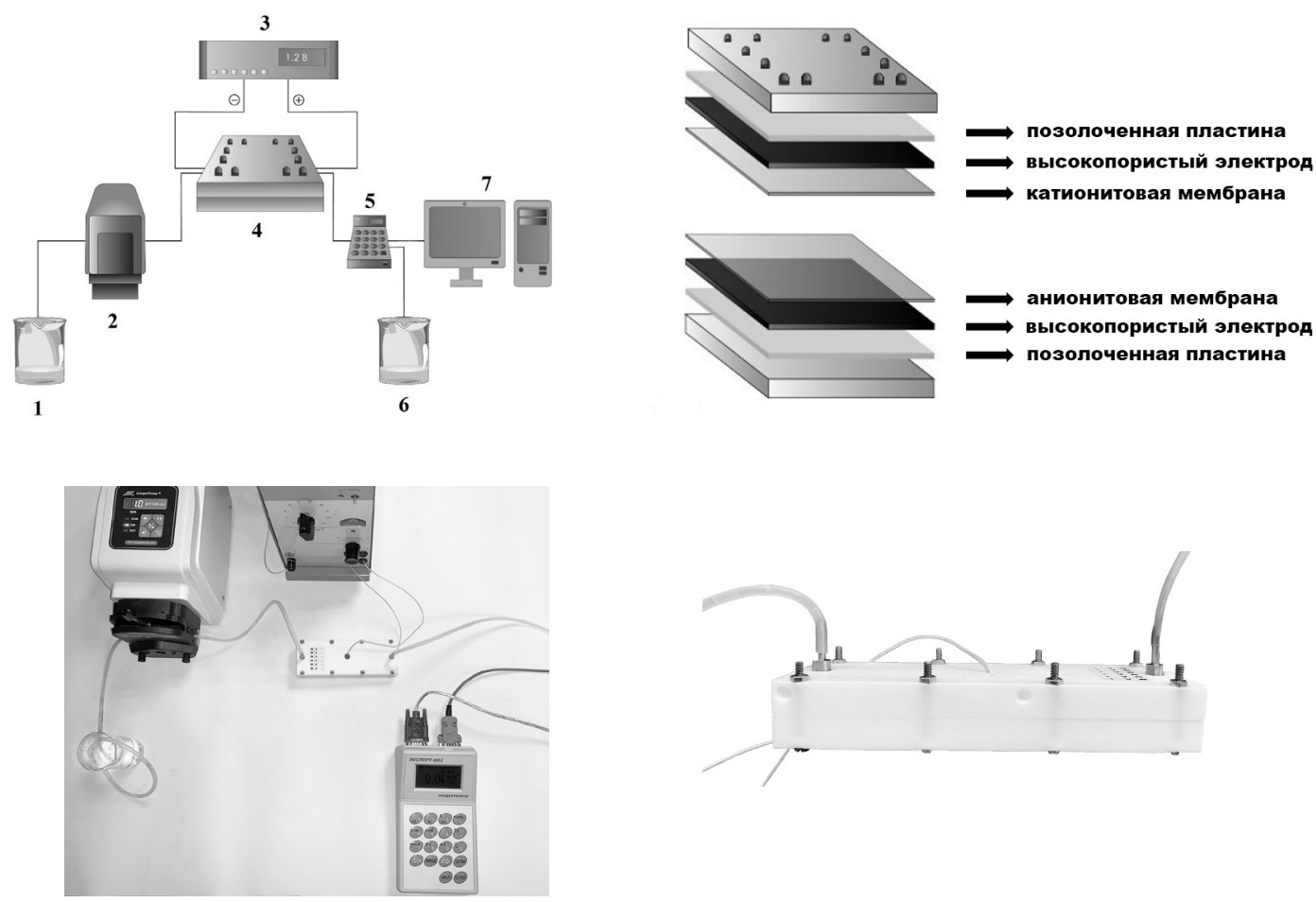

a

Рис. 8. Схема и фото лабораторной установки (а) и электрохимической ячейки (б): 1 - раствор соли; 2 - перистальтический насос; 3 - источник питания; 4 - ячейка; 5 - кондуктометр; 6 - слив раствора; 7 - компьютер.

Результаты эксперимента, приведенные ниже, были получены при соблюдении следующих условий: сначала через ячейку пропускали избыточное количество исходного модельного раствора хлорида натрия, чтобы обеспечить равновесие между раствором и фазой пористого электрода; затем на электроды подавали внешнее постоянное напряжение (не более $1.2 \mathrm{~B}$, чтобы избежать электролиза и образования пузырьков газа). При этом полярность выбирали так, чтобы катодный потенциал подавался со стороны катионитовой мембраны. В ходе динамического эксперимента по емкостной деионизации продолжали пропускать раствор через ячейку до тех пор, пока электропроводность (концентрация соли) на входе и выходе из ячейки не становилась одинаковой, после чего только меняли полярность внешнего напряжения, приложенного к электродам. В статическом режиме изменение полярности производили после достижения минимального значения электропроводности.

Углеродные аэрогели в процессе емкостной (мембранной) деионизации

Результаты экспериментов с легким аэрогелем. (Было бы правильнее называть полученные материалы после их набухания в водной среде «гидрогелями», но, следуя литературе, оставим обозначение «аэрогели»). На рисунке 9 приведены кривые изменения электропроводности раствора в закрытой электрохимической ячейке на разных стадиях процесса емкостной (мембранной) деионизации в статическом режиме. Отношение электропроводности раствора в определенный момент времени к электропроводности исходного раствора хлорида натрия равно отношению соответствующих значений концентрации соли. Сначала концентрация хлорида натрия 
уменьшается, а после изменения полярности электродов она возвращается к своему первоначальному значению. Процесс обратимый с точки зрения количества сорбированной и десорбированной соли на разных стадиях процесса. Удельная электросорбционная емкость аэрогеля для сорбированной соли (на 1 г сухого материала электрода), рассчитанная по этим кривым, составляет 62 мг/г, и это значение, принимая во внимание равновесную концентрацию соли в жидкой фазе, превышает все известные и ранее опубликованные значения емкостей [11-13].

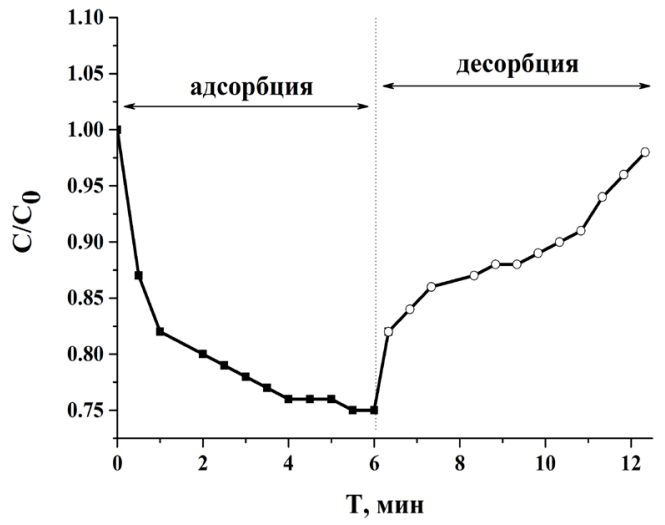

Рис. 9. Изменение концентрации

$\mathrm{NaCl}$ в зависимости от времени в статическом режиме: $\mathrm{C}_{0}=1.0$ г/дм ${ }^{3}$

$\left(0.017\right.$ экв/дм $\left.{ }^{3}\right)$; $\mathrm{U}=1.2 \mathrm{~B}$; размеры пористого электрода (см): $3 \times 3 \times 0.5$; расстояние между электродами: 1 см.

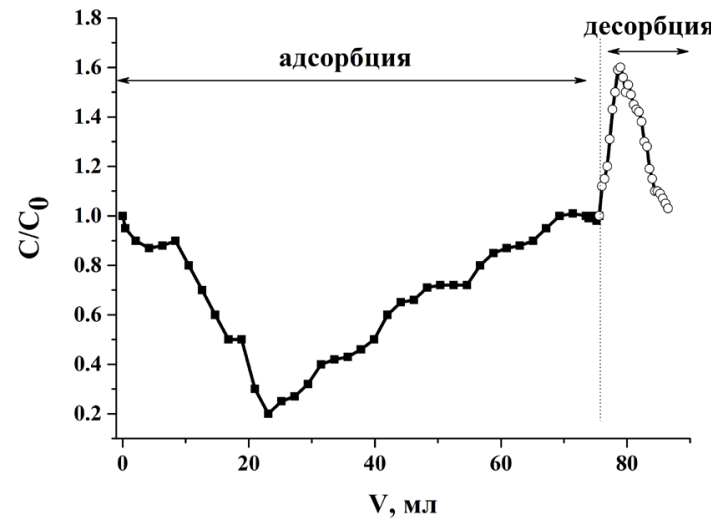

Рис. 10. Изменение концентрации $\mathrm{NaCl}$ в зависимости от времени в динамическом режиме: $\mathrm{C}_{0}(\mathrm{NaCl})=0.1 \Gamma /$ дм $^{3}$ $(0.0717$ экв/дм³ $) ; \mathrm{U}=1.2 \mathrm{~B} ;$ размеры пористого электрода (см): $3 \times 3 \times 0.5$; расстояние между электродами: $0.5 \mathrm{~cm}$; скорость потока: $0.42 \mathrm{~cm}^{3} / \mathrm{Mин}$.

Рассмотрим, как те же электроды работают в динамическом режиме. Для достижения большего эффекта деминерализации в эксперименте был взят более разбавленный раствор соли. Полученные результаты представлены на рисунке 10 . Асимметричность динамической кривой на рисунке 10, из которой мы видим, что количество соли на стадиях сорбции и десорбции отличается, не связана с обратимостью или необратимостью процессов в ЕМД, но указывает на то, что имеет место другой тип или дополнительные факторы процесса массопереноса. Это стало понятным после вскрытия ячейки в конце цикла сорцбии-десорбции, когда обнаружилась значительная усадка пористого электрода. Этот эффект можно объяснить параллельными и паразитными процессами массопереноса, а именно, осмотическим переносом воды из электрода в межэлектродное пространство на стадии накопления десорбированной соли. Структура легкого материала (с объемом «скелета» менее $1 \%$ от общего объема) является жесткой, при этом материал является хрупким, его механичемкая прочность, по-видимому, недостаточна и разрушается при осмотическом переносе воды. Полученные результаты показывают, что слишком большая пористость, как и жесткая структура исходного аэрогеля, не являются положительными факторами для емкостной деионизации.

Результаты, полученные с помощью электродов из плотного аэрогеля. На рисунке 11 показана кривая изменения концентрации раствора на выходе из электрохимической ячейки в динамическом процессе ЕМД с использованием электродов из образца плотного аэрогеля. 


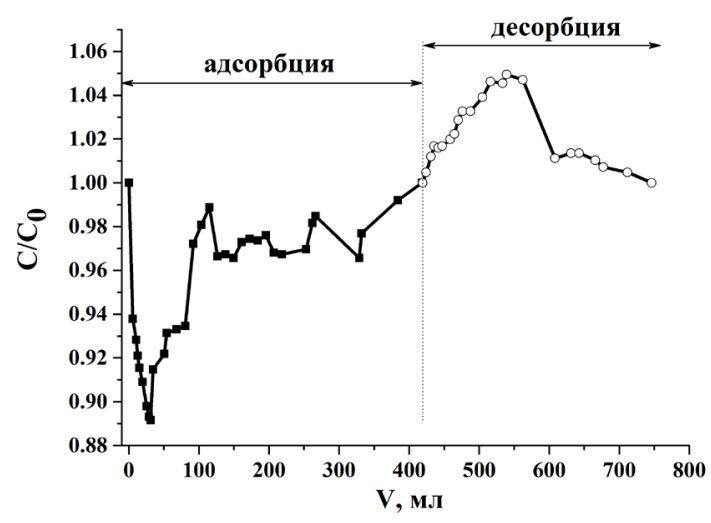

Рис. 11. Изменение концентрации $\mathrm{NaCl}$ в зависимости от объема раствора, прошедшего через ячейку, в динамическом режиме: $\mathrm{C}_{0}(\mathrm{NaCl})=1 \Gamma /$ дм $^{3}$ (0.717 экв/дм $\left.{ }^{3}\right) ; \mathrm{U}=1.2 \mathrm{~B}$; размеры пористых электродов: $3 \times 3 \times 0.5$ см; расстояние между электродами: $0.5 \mathrm{~cm}$; скорость потока: $0.69 \mathrm{~cm}^{3} / \mathrm{Mин}$.

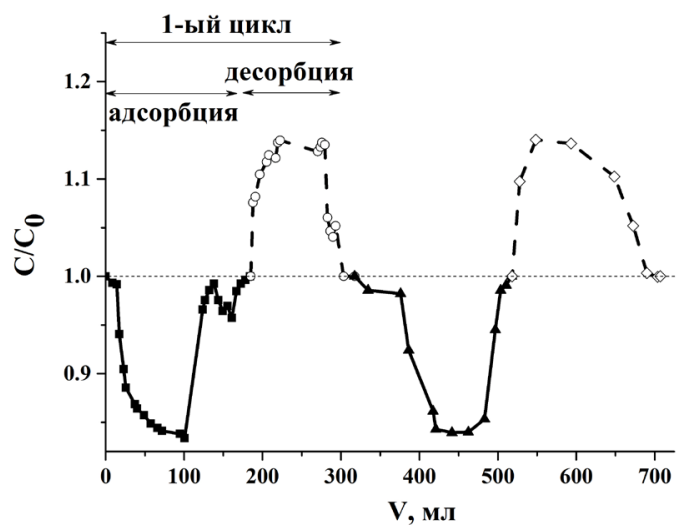

Рис. 12. Изменение концентрации $\mathrm{NaCl}$ в зависимости от времени в динамическом режиме: $\mathrm{C}_{0}(\mathrm{NaCl})=1 г /$ дм $^{3}$ $\left(0.717\right.$ экв/дм $\left.{ }^{3}\right) ; \mathrm{U}=1.2 \mathrm{~B}$; размеры пористых электродов (см): $3 \times 3 \times 0.5$; скорость потока: $0.69 \mathrm{~cm}^{3} /$ мин; расстояние между электродами: $0.2 \mathrm{~cm}$.

Процесс на этих электродах почти симметричный, однако, он неравномерный и, как правило, очень медленный (с учетом скорости потока раствора через ячейку). Процесс становится быстрее и эффективнее, если зазор между электродами в электрохимической ячейке уменьшается. На рисунке 12 показана зависимость концентрации от объема раствора, прошедшего через электрохимическую ячейку, для двух последовательных циклов сорбции-десорбции после уменьшения ширины зазора с 0.5 см до 0.2 см. Процесс ЕМД становится симметричным, полностью обратимым и повторяющимся.

Можно предположить на основе этих данных, что в апробированных условиях лимитирующей стадией в динамическом процессе емкостной деионизации является перенос в межэлектродном растворе, т.е. при использовании композитных аэрогелей в качестве электродов для ЕМД диффузионные процессы в пористом монолите не ограничивают скорость деионизации воды. Среднее значение электросорбционной емкости, рассчитанное по экспериментальным данным, представленным на Рисунке 12 , составляет 25.3 мг/г на единицу массы сухого аэрогеля. Эта величина превышает или сравнима со значениями емкости (в расчете на единицу массы), полученными ранее в работах $[11,12]$.

В таблице ниже приведены значения емкостей электродных материалов, полученных и исследованных в данной работе, в сравнении с литературными данными (легкий аэрогель не учитывали, поскольку его нельзя было тестировать в динамическом режиме процесса емкостной мембранной деионизации).

Полученные данные показывают, что синтезированные в рамках этой работы материалы и электроды, полученные на их основе, эффективны в процессе емкостной деионизации воды. Результаты исследований сравнимы или даже превосходят лучшие результаты, опубликованные в литературе. Удельные сорбционные емкости на единицу объема (см. таблицу 5), представленные в нижней строке, были рассчитаны с использованием значений плотностей сухих образцов материалов, к примеру, $0.41 \mathrm{мг} / \mathrm{cm}^{3}$ - для аэрогеля в публикации [11]. 
Таблица 5. Удельная емкость электродов из разных материалов в процессах ЕД и ЕМД (раствор $\mathrm{NaCl}=1000 \mathrm{мг} /$ дм$^{3}$ ).

\begin{tabular}{|c|c|c|c|c|c|}
\hline Образец & $\begin{array}{c}\text { Углеродный аэро- } \\
\text { гель на основе акти- } \\
\text { вированных волокон } \\
{[11]}\end{array}$ & $\begin{array}{c}\text { Аэрогель } \\
\text { на основе } \\
\text { МУНТ и } \\
\text { графена } \\
{[12]}\end{array}$ & $\begin{array}{c}\text { Порошок } \\
\text { МУНТ [12] }\end{array}$ & $\begin{array}{c}\text { Порошок } \\
\text { графена } \\
{[12]}\end{array}$ & $\begin{array}{c}\text { Плотный } \\
\text { аэрогель } \\
\text { (данная } \\
\text { работа) }\end{array}$ \\
\hline $\begin{array}{c}\text { Емкость, } \\
\text { мг/г }\end{array}$ & 14.2 & 24.5 & 17.5 & 12.0 & 25.3 \\
\hline $\begin{array}{c}\text { Емкость } \\
\text { мг/см }{ }^{3}\end{array}$ & 5.7 & 1.0 & - & - & 3.0 \\
\hline
\end{tabular}

Довольно хорошие результаты по электросорбционной емкости нескольких типов композиционных материалов были получены в работе [13] для раствора хлорида натрия с электропроводностью 100 мкСм/см (что соответствует примерно $50 \mathrm{мг} /$ дм $^{3}$ ). Однако мы не можем сравнивать эти данные с результами, приведенными в таблице 5. Следует предположить, что новые графен-содержащие композиционные материалы, полученные в этой работе, могут быть перспективны для использования в других областях, к примеру, для «зеленой» энергетики и защиты окружаюшей среды [14].

\section{Заключение}

Предложены новые способы синтеза высокопористых композитных аэрогелей в форме монолита с каркасом, образованным из восстановленного оксида графена и углеродных нанотрубок. Предложена простая методика гидрофилизации синтезированных образцов. Изготовлены новые электродные материалы для электросорбции и деионизации воды, а полученные материалы исследованы и испытаны в электрохимических ячейках для емкостной мембранной деионизации.

Сверхпористые (более 99\%) углеродные композитные аэрогели с плотностью

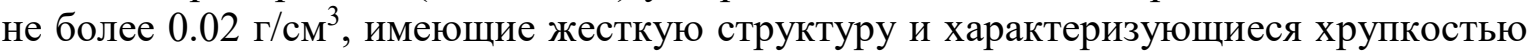
образующихся монолитов, не эффективны для процессов ЕМД. Эластичные аэрогели с более плотной структурой, пористостью до 95\% и плотностью не менее 0.12 г/см ${ }^{3}$, синтезированные в присутствии поливинилового спирта, имеют относительно высокую электросорбционную емкость к хлориду натрия, к примеру, при концентрации раствора - 1 г/дм ${ }^{3}$, емкость достигает $25 \mathrm{мг} / г\left(3 \mathrm{мг} / \mathrm{cm}^{3}\right)$. Они также демонстрируют хорошую стабильность, что делает их очень перспективными для использования в технологиях емкостной деионизации. Предполагается, что при использовании композитных аэрогелей в качестве электродов для ЕМД диффузионные и электродиффузионные процессы в пористом монолите (в апробированных условиях) не лимитируют скорость деионизации воды.

\section{Список литературы}

1. Oren Y. // Desalination. 2008. Vol. 228. pp. 10-29.

2. Porada S., Zhao R., Van der Wal A., Presser V. et al. // Progress in Materials Science. 2013. Vol. 58. pp. 1388-1422.

3. Andelman M.D., Walker G.S. Charge barrier flow-through capacitor. Patent US. No 6709560B2, 2004.

4. Suss M.E., Porada S., Sun X., Biesheuvel P.M. et al. // Energy\&Environmental Science. 2015. Vol. 8. pp. 2296-2319.

5. Wenchao W., Ruiyang Z., Wei Li, Hao L. et al. // Environmental Science: Nano. 2016. Vol. 3. pp. 107-113.

6. Бахия Т., Хамизов Р.Х., Конов М.А., Бавижев М.Д. Патент РФ. № 2662 484. 2018. 
7. Akhavan O., Ghaderi E., Aghayee S., Fereydooni Y. et al. // Journal of Materials Chemistry. 2012. Vol. 22, pp. 13773-13781.

8. Huang J., Li Zh., Wu X., Wang J. et al. // The Journal of Physical Chemistry C. 2019. Vol. 123. pp. 3781-3789.

9. Haiyan S., Zhen X., Chao G. // Advanced materials. 2013. Vol. 25, pp. 2554-2560.

10.Tokmachev M.G., Tikhonov N.A. // Journal of Mathematical Chemistry. 2019. Vol. 57. No 10. pp. 2169-2181.
11.Marmanis D., Christoforidis A., Ouzounis K., Dermentzis K. // Global NEST Journal. 2014. Vol. 16. No. 4. pp. 609-615.

12.Zhuyin S., Qinghan M., Xuetong Z., Rui M. et al.// Journal of Materials Chemistry. 2012. Vol. 22. pp. 8767-8771.

13.Zhu G., Wang W.Q., Li X., Zhu J. et al. // RSC Advances. 2016. Vol. 6. pp. 5817-5823.

14.Fan W., Zhang L., Liu T. // Graphenecarbon nanotube hybrids for energy and environmental applications Springer. 2017. C. 1-104.

\title{
Composite graphene-containing porous materials used for electrosorption and capacitive deionisation
}

\author{
(C) 2020 Bakhia T. ${ }^{1}$, Khamizov R.Kh. ${ }^{2}$, Bavizhev Z.R. ${ }^{3}$ \\ ${ }^{1}$ Lomonosov Moscow State University, Moscow \\ ${ }^{2}$ Vernadsky Institute (GEOKHI) RAS, Moscow \\ ${ }^{3}$ «SPE «Radiy», Moscow
}

Highly porous aerogels based on carbon nanomaterials are promising materials that can be used in new electrochemical technologies. Capacitive deionisation is a technology for removing ion species from aqueous solutions. The removal is performed by applying low external voltage to the electrodes with the high specific surface area. This is one of the most advanced methods for the desalination of low-mineralised solutions. The main problem pertaining to capacitive deionisation is the need to obtain affordable electrode materials with high porosity, high electrical conductivity, high hydrophilicity, and good mechanical properties, which can be used in a large number of adsorption-desorption cycles. Among the most promising materials are carbon aerogels.

The article describes the process of synthesising new materials, highly porous monolithic composite aerogels with 3D structure formed by reduced graphene oxide and nanotubes. The electrosorption properties of the materials were studied in a series of experiments, where the said monoliths were used as electrodes for membrane capacitive deionisation.

The article suggests new methods of synthesising highly porous composite carbon aerogels with 3D network structure formed by reduced graphene oxide and carbon nanotubes. Simple techniques for the hydrophilisation of the synthesised samples were developed. New electrode materials for electrosorption were created, studied, and tested in electrochemical cells for membrane capacitive deionisation. Super-porous (over 99\%) composite carbon aerogels with a density under $0.02 \mathrm{~g} / \mathrm{cm}^{3}$, rigid structure, and fragile monoliths are not effective during membrane capacitive deionisation. More dense elastic aerogels with $95 \%$ porosity and a density of at least $12 \mathrm{~g} / \mathrm{cm}^{3}$, synthesised in the presence of polyvinyl alcohol, have relatively high electrosorption capacity with respect to sodium chloride. For instance, when the concentration of the solution is 1 $\mathrm{g} / \mathrm{dm}^{3}$, the capacity of the material is $25 \mathrm{mg} / \mathrm{g}\left(3 \mathrm{mg} / \mathrm{cm}^{3}\right)$. The synthesised aerogels are also quite stable, which makes them a promising material for capacitive deionisation.

Keywords: graphene, aerogel, mesoporous carbon, composite, capacitive deionisation.

\section{References}

1. Oren Y., Desalination, 2008, Vol. 228, pp. 10-29, DOI: 10.1016/j.desal.2007.08. 005, available at: https://doi.org/10.1016/ j.desal.2007.08.005 (accessed 15.08.2008).

2. Porada S., Zhao R., Van der Wal A., Presser V. et al., Progress in Material Science, 2013, Vol. 58, pp. 1388-1422, DOI: 10.1016/j.pmatsci.2013.03.005, available at: https://doi.org/10.1016/j.pmatsci.2013.03.00 5 (accessed 10.2013).
3. Andelman M.D., Walker G.S. Charge barrier flow-through capacitor. Patent US, No 6709560B2, 2004.

4. Suss M.E., Porada S., Sun X., Biesheuvel P.M., et al., Energy \& Environmental Science, 2015, Vol. 8, pp. 2296-2319, DOI: 10.1039/C5EE00519A, available at: https://doi.org/10.1039/C5EE00519A (accessed 05.05.2015).

5. Wenchao W., Ruiyang Z., Wei Li, Hao L. et al., Environmental Science: Nano, 2016, Vol. 
3, pp. 107-113, DOI: 10.1039/C5EN00125K, available at: https://doi.org/10.1039/C5EN00125K (accessed 2016).

6. Bakhia T., Khamizov R.Kh., Konov M.A., Bavizhev M.D. Patent RF, no. 2662 484, 2018.

7. Akhavan O., Ghaderi E., Aghayee S., Fereydooni Y. et al., J. Mater. Chem., 2012, Vol. 22, pp. 13773-13781, DOI: 10.1039/C2JM31396K, available at: https://doi.org/10.1039/C2JM31396K (accessed 20.07.2012).

8. Huang J., Li Zh., Wu X., Wang J., Yang Sh., J. Phys. Chem. C, 2019, Vol. 123, pp. 3781-3789.

9. Haiyan S., Zhen X., Chao G., Advanced materials, 2013, Vol. 25, pp. 2554-2560, DOI: 10.1002/adma.201204576, available at: https://doi.org/10.1002 /adma.201204576 (accessed 2013).

10.Tokmachev M.G., Tikhonov N.A., J. of Mathematical Chemistry, 2019, Vol. 57, No.

Бахия Тамуна - аспирантка химического факультета МГУ имени М.В. Ломоносова, Москва

Хамизов Руслан Хажсетович - заведующий лабораторией ГЕОХИ РАН, д.Х.н., Москва

Бавижев Заур Рамазанович - старший научный сотрудник НИЦ АО «НПП «Радий», Москва
10, pp. 2169-2181, DOI: 10.1007/s10910-01901064-7, available at: https://doi.org/10.1007/s10910-019-01064-7 (accessed 12.09.2019).

11. Marmanis D., Christoforidis A., Ouzounis K., Dermentzis K., Global NEST Journal, 2014, Vol. 16, No4, pp. 609-615, DOI: 10.30955/gnj.001253, available at: https://doi.org/10.30955/gnj.001253 (accessed 23.05.2014).

12. Zhuyin S., Qinghan M., Xuetong Z., Rui M. et al., J. of Mater. Chem., 2012, Vol. 22, pp. 8767-8771, DOI: 10.1039/C2JM00055E available at: https://doi.org/10.1039/C2JM00055E (accessed 15.03.2012).

13.Zhu G., Wang W.Q., Li X., Zhu J. et al., RSC Advances, 2016, Vol. 6, pp. 5817-5823.

14.Fan W., Zhang L., Liu T., Graphenecarbon nanotube hybrids for energy and environmental applications Springer, 2017, pp. 1104. available at:https://doi.org/10.1007/978981-10-2803-8(accessed 2017).

Bakhia Tamuna - Graduate student of the Department of Chemistry, Lomonosov Moscow State University, Moscow, crbakhia@list.ru

Khamizov Ruslan Kh. - Head of the laboratory of the Vernadsky Institute (GEOKHI) RAS, D.Sc. (Chem.), Moscow, khamiz@,mail.ru

Bavizhev Zaur R. - Senior Research Scientist of the SC “SPE "Radiy”, Moscow, zu588@mail.ru 